\title{
What's in a number? The interesting challenge of knowledge diffusion
}

\author{
Anjala S. Krishen ${ }^{1} \cdot$ Maria Petrescu $^{2,3}$
}

Published online: 27 February 2020

(c) Springer Nature Limited 2020

A recent inquiry into how Journal of Marketing Analytics articles are faring with our reader base indicates that our editorials are being downloaded quite frequently. Anyone who has published research, written a book, tweeted an idea, posted a picture, or made any attempt to be read, seen, or heard knows that numbers ultimately provide comparative information. Newer forms of information (likes, loves, anger emojis, and so on) in addition to comments allow people to get feedback, whether it is warranted or not. No matter what realm we investigate, quantitative indicators (key performance metrics) help clarify whether performance met expectations. The recent Krishen and Petrescu (2019) editorial entitled, Data-driven decision making: Implementing analytics to transform academic culture, mentions performance and productivity (merit-based allocation), demographics (intersectional and inclusive), and creativity and motivation (transformational culture) as pillars of resource allocation in organizations, specifically in universities. Expanding beyond that domain, individuals are constantly challenged to produce meaningful knowledge, spread it either locally or globally, and tie it to a performance-based reward. Organizations must then commit to fair and equitable methods of utilizing metrics and analytics over time to allocate resources.

Sharing knowledge is one of the most persistent challenges of humanity and newer methods of doing so are constantly surfacing over time. Knowledge-seeking consumers utilize traditional methods including journals, news outlets, and websites as well as social media tools such as Facebook, Twitter, and LinkedIn to gather and disseminate knowledge.

Maria Petrescu

maria.petrescu@icn-artem.com

Anjala S. Krishen

Anjala.krishen@unlv.edu

1 Lee Business School, University of Nevada, Las Vegas, NV, USA

2 ICN Business School Artem, CEREFIGE Laboratoire, Nancy, France

3 Colorado State University Global, Aurora, CO, USA
In the process of sharing their knowledge, contributors and managers pay special attention to metrics such as downloads, re-tweets, likes, shares, and so on (Huang et al. 2019; Shiau et al. 2018). Social media analytics such as "likes" are trusted by consumers, a finding that can have both negative and positive consequences (Seo et al. 2019). Research also indicates that social network structure plays a major role in connecting knowledge seekers to knowledge providers and ultimately diffusing knowledge (Qiao et al. 2019). The challenge therefore lies not only in producing knowledge, but also in sharing and promoting it outside of a small network of friends. This call also expands to the production of engaged scholarship; this is the scholarship that first addresses management gaps and issues and second can be mobilized and applied in organizations (Elbanna et al. 2019; Wolfberg and Lyytinen 2017).

Figure 1 presents an expansion of the IDIKC (intersectional diverse and inclusive knowledge creation) framework (Krishen et al. 2019) which moves from knowledge creation to knowledge sharing/dissemination. This process can also be unfortunate since the creation and dissemination of knowledge from diverse and inclusive perspectives is difficult due to institutionalized power structures (Grier 2019; King et al. 2018). In this framework, even if analytics are not used as a sole determinant of the importance of knowledge, they do provide a data-driven metric (Baron \& RussellBennett, 2016). 


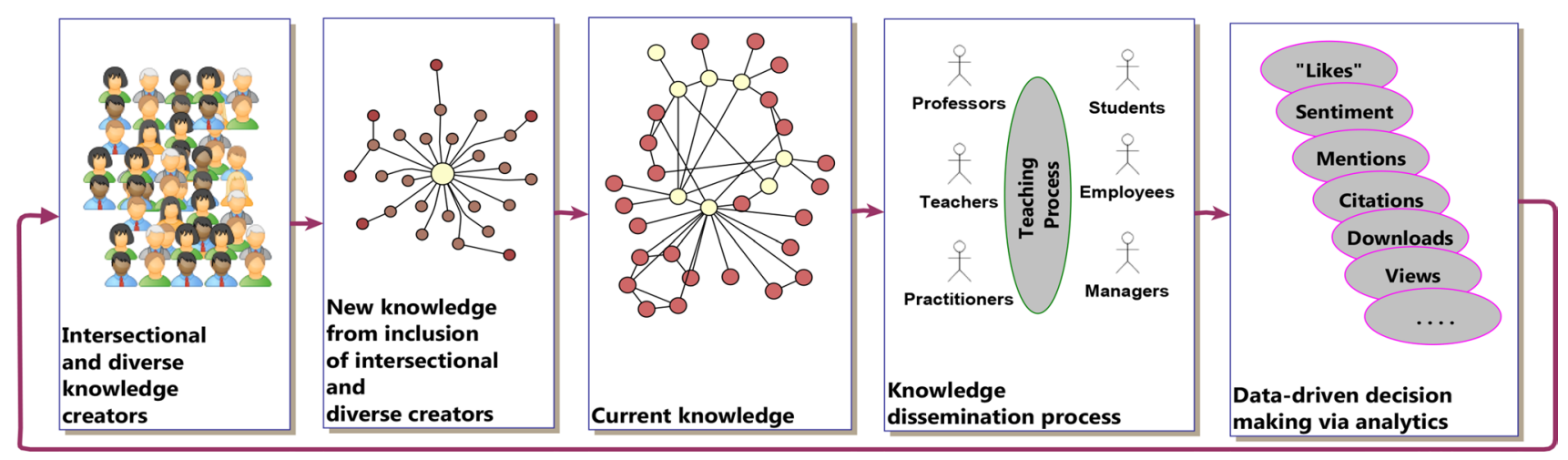

Fig. 1 Spreading knowledge with data-driven decisions

\section{References}

Baron, S., and R. Russell-Bennett. 2016. Editorial: The changing nature of data. Journal of Services Marketing, 30(7): 673-675. https:// doi.org/10.1108/JSM-08-2016-0292.

Elbanna, A., D. Bunker, L. Levine, and A. Sleigh. 2019. Emergency management in the changing world of social media: Framing the research agenda with the stakeholders through engaged scholarship. International Journal of Information Management 47: 112120. https://doi.org/10.1016/j.ijinfomgt.2019.01.011.

Grier, S.A. 2019. Marketing inclusion: A social justice project for diversity education. Journal of Marketing Education. https://doi. org/10.1177/0273475319878829.

Huang, L., A. Clarke, N. Heldsinger, and W. Tian. 2019. The communication role of social media in social marketing: A study of the community sustainability knowledge dissemination on LinkedIn and Twitter. Journal of Marketing Analytics 7 (2): 64-75. https:// doi.org/10.1057/s41270-019-00053-8.

King, E.B., D.R. Avery, M.R. Hebl, and J.M. Cortina. 2018. Systematic subjectivity: How subtle biases infect the scholarship review process. Journal of Management 44 (3): 843-853. https://doi. org/10.1177/0149206317743553.

Krishen, A.S., and M. Petrescu. 2019. Data-driven decision making: Implementing analytics to transform academic culture. Journal of Marketing Analytics 7 (2): 51-53.

Krishen, A.S., E.A. Robleto, J. Meza, and J. Santana. 2019. From homophily to reality: Proposing the intersectional, diverse, and inclusive knowledge creation framework. In Marketing and humanity: Discourses in the real world, ed. A.S. Krishen and O. Berezan, 98-117. Newcastle upon Tyne: Cambridge Scholars Publishing.

Qiao, T., W. Shan, M. Zhang, and C. Liu. 2019. How to facilitate knowledge diffusion in complex networks: The roles of network structure, knowledge role distribution and selection rule. International Journal of Information Management 47: 152-167. https:// doi.org/10.1016/j.ijinfomgt.2019.01.016.
Seo, Y., J. Kim, Y.K. Choi, and X. Li. 2019. In "likes" we trust: Likes, disclosures and firm-serving motives on social media. European Journal of Marketing 53 (10): 2173-2192. https://doi. org/10.1108/ejm-11-2017-0883.

Shiau, W.L., Y.K. Dwivedi, and H.H. Lai. 2018. Examining the core knowledge on facebook. International Journal of Information Management 43: 52-63. https://doi.org/10.1016/j.ijinf omgt.2018.06.006.

Wolfberg, A., and K. Lyytinen. 2017. Narrowing the dissemination gap: Genres for practitioner scholarship. Engaged Management ReView. https://doi.org/10.28953/2375-8643.1034.

Publisher's Note Springer Nature remains neutral with regard to jurisdictional claims in published maps and institutional affiliations.

Anjala S. Krishen is a Professor of Marketing and International Business and Special Advisor to the Dean for Research at University of Nevada, Las Vegas, has a B.S. in Electrical Engineering from Rice University, and an M.S. Marketing, MBA, and Ph.D. from Virginia Tech. She held management positions for 13 years before pursuing a doctorate. As of 2019, she has published over 50 peer-reviewed journal papers in journals including Journal of Business Research, Psychology \& Marketing, Information \& Management, European Journal of Marketing, Journal of Travel \& Tourism Marketing, and Journal of Marketing Education. In 2016, she gave a TEDx talk (at UNR) titled "Opposition: The light outside of the dark box," and a UNLV Creates speech entitled "Consuming to Creating, Watching to Doing, Seeing to Being." To date, she has completed over 55 marathons, seven ultramarathons, three 100 milers, and has a black belt in Taekwondo.

Maria Petrescu is an Associate Professor of Marketing at ICN Business, School Artem, Nancy, France. Her main research areas include marketing analytics and digital marketing. She has published articles in journals such as Psychology \& Marketing, the Journal of Marketing Management, Public Management Review, Journal of Product and Brand Management, the Journal of Retailing and Consumer Services, and the Journal of Internet Commerce. 